\title{
Generation of novel cationic antimicrobial peptides from natural non-antimicrobial sequences by acid-amide substitution
}

Satoshi Ueno', Masaomi Minaba', Yuji Nishiuchi², Misako Taichi², Yasushi Tamada', Toshimasa Yamazaki ${ }^{1}$, Yusuke Kato ${ }^{1 *}$

\begin{abstract}
Background: Cationic antimicrobial peptides (CAMPs) are well recognized to be promising as novel antimicrobial and antitumor agents. To obtain novel skeletons of CAMPs, we propose a simple strategy using acid-amide substitution (i.e. Glu $\rightarrow$ Gln, Asp $\rightarrow$ Asn) to confer net positive charge to natural non-antimicrobial sequences that have structures distinct from known CAMPs. The potential of this strategy was verified by a trial study.

Methods: The pro-regions of nematode cecropin P1-P3 (P1P-P3P) were selected as parent sequences. P1P-P3P and their acid-amide-substituted mutants (NP1P-NP3P) were chemically synthesized. Bactericidal and membranedisruptive activities of these peptides were evaluated. Conformational changes were estimated from far-ultraviolet circular dichroism (CD) spectra.

Results: NP1P-NP3P acquired potent bactericidal activities via membrane-disruption although P1P-P3P were not antimicrobial. Far-ultraviolet CD spectra of NP1P-NP3P were similar to those of their parent peptides P1P-P3P, suggesting that NP1P-NP3P acquire microbicidal activity without remarkable conformational changes. NP1P-NP3P killed bacteria in almost parallel fashion with their membrane-disruptive activities, suggesting that the mode of action of those peptides was membrane-disruption. Interestingly, membrane-disruptive activity of NP1P-NP3P were highly diversified against acidic liposomes, indicating that the acid-amide-substituted nematode cecropin proregion was expected to be a unique and promising skeleton for novel synthetic CAMPs with diversified membrane-discriminative properties.

Conclusions: The acid-amide substitution successfully generated some novel CAMPs in our trial study. These novel CAMPs were derived from natural non-antimicrobial sequences, and their sequences were completely distinct from any categories of known CAMPs, suggesting that such mutated natural sequences could be a promising source of novel skeletons of CAMPs.
\end{abstract}

\section{Background}

Cationic antimicrobial peptides (CAMPs) are well recognized to be promising as novel antimicrobial and antitumor agents. Natural CAMPs are structurally much diverse (e.g., linear cationic $\alpha$-helical CAMPs, those enriched for specific amino acids, and those containing disulphide bonds and stable $\beta$-sheets) [1]. Because each category exhibits characteristic antimicrobial properties,

\footnotetext{
* Correspondence: kato@affrc.go.jp

${ }^{1}$ National Institute of Agrobiological Sciences, Oowashi 1-2, Tsukuba, Ibaraki 305-8634, Japan

Full list of author information is available at the end of the article
}

numerous researchers have tried to identify novel skeletons of natural CAMPs from various organisms over the last two decades. Many categories of CAMPs were identified in the last century. However, most CAMPs which were recently found were categorized in known groups, suggesting that the search for novel skeletons may have almost reached its limit. To find novel skeletons, nonnatural sequences have been also explored [2]. A major trial is combinatorial chemistry or similar approach such as construction of random peptide libraries and high-throughput screening [3-9]. Although these approaches produced some novel CAMPs, they are

\section{Biomed Central}


effective only for short sequences. However, several major categories of CAMPs are larger peptides that contain specific higher order structures as mentioned above. Introduction of non-natural peptide mimics is an alternative strategy [10-12]. This is an excellent strategy which can overcome the limitations inherent to peptides physical characteristics. A demerit of this strategy is that those peptide mimics cannot be prepared as recombinant products by ribosomal syntheses which can produce natural CAMPs.

In this study, we propose a simple strategy to obtain novel larger skeletons of CAMPs which only contain natural amino acids using acid-amide substitution (i.e. Glu $\rightarrow$ Gln, Asp $\rightarrow$ Asn), as described below.

(1) CAMPs are basic molecules. The positive charge is essential for antimicrobial activity, but most natural proteins/peptides are not basic.

(2) Rather than being limited to a specific skeleton, natural CAMPs are structurally diverse. Novel skeletons of CAMPs can be screened from modified nonbasic sequences that have structures distinct from known CAMPs by acquisition of net positive charge.

(3) As such nonbasic parent sequences, natural nonantimicrobial peptides or parts of proteins can be used.

(4) Substituting acidic residues with counterpart amides (i.e. Glu $\rightarrow$ Gln, Asp $\rightarrow$ Asn) can neutralize negative charges and confer net positive charge if the parent sequences contain substantial basic residues. Such substitution is "conservative," which minimally affects the unique structure of parent sequences in most cases. Introduction of basic residues at random positions is unfavorable because the sequences become uniform with increasing substitution and the unique structures of parent sequences are lost.

As a trial study, the pro-regions of nematode cecropins were selected as parent sequences. Nematode cecropins are natural antimicrobial peptides [13-15]. Four nematode cecropins (P1-P4) have been identified in the pig roundworm, Ascaris suum [15]. A pro-region (26-30 residues long) is conserved at the $\mathrm{C}$ terminus of nematode cecropin precursors (Figure 1)[15]. It contains 4-6 acidic residues that might interact with mature peptides to suppress their antimicrobial activity in the precursor form [16]. Basic residues including a unique tribasic site, $(H / R) R R$, are also present at the $\mathrm{N}$ terminus. These sequences are expected to be promising parent sequences because the pro-regions have been estimated to acquire strong net positive charges by acidamide substitution.

\section{Methods} Peptides

Peptides used in this study were prepared at Biologica Co., (Nagoya, Japan). Briefly, the peptides were synthesized by the Fmoc method, and purified by reverse phase HPLC. The products were confirmed by time-of-flight mass spectrometry on a Voyager DE Mass Spectrometer, Applied Biosystems (Foster city, CA, USA).

\section{Microorganisms}

E. coli JM109 was purchased from Takara (Otsu, Japan). Saccharomyces cerevisiae MAFF113011 was obtained from the National institute of Agrobiological Sciences, Ibaraki, Japan. Other strains described below were transferred from the National Institute of Technology and Evaluation, Kazusa, Japan: Staphylococcus aureus IFO12732, Bacillus subtilis IFO3134, Micrococcus luteus IFO12708, Pseudomonas aeruginosa IFO3899, Salmonella typhimurium IFO13245 and Serratia marcescens IFO3736.

\section{Microbicidal assay}

Microbicidal assay was performed as previously described [17]. A low ionic strength condition was used to detect bactericidal activity with higher sensitivity. Briefly, each microbial strain in the mid-exponential phase was suspended in $10 \mathrm{mM}$ Tris/ $\mathrm{HCl}, \mathrm{pH}$ 7.5. The microbial suspension was mixed with peptides. After $2 \mathrm{~h}$ incubation, the suspension was diluted 1,000 times and inoculated on to plates of IFO702 medium (1\% polypeptone, $0.2 \%$ yeast extract, $0.1 \% \mathrm{MgSO}_{4} 7 \mathrm{H}_{2} \mathrm{O}, 2 \%$ agar). The numbers of colonies were counted, and a plot of peptide concentration vs colony number was created.

\section{Hemolytic assay}

Hemolytic assay was performed as previously described [18]. Human erythrocytes were used. Hemolysis was estimated as the leakage of haemoglobin. The erythrocytes were washed and resuspended in $10 \mathrm{mM}$ Tris- $\mathrm{HCl}$, $\mathrm{pH} 7.5$, containing $308 \mathrm{mM}$ sucrose. The erythrocyte suspension was diluted by $30 \%$. The diluted suspension was mixed with the equal volume of peptide solution dissolved in the same buffer. After $0.5 \mathrm{~h}$ of incubation, the test suspension was centrifuged to remove the intact erythrocytes. The supernatant was diluted, and $A_{540}$ was measured. The hemolysis caused by pure water was defined as 100\% lysis. Amphotericin B was used as a positive control.

\section{Cytoplasmic membrane permeability assay}

Cytoplasmic membrane permeabilization of $S$. aureus was determined with a voltage-sensitive dye, diS- $\mathrm{C}_{3}-(5)$ [19]. Bacteria in the mid-exponential phase were suspended in $10 \mathrm{mM}$ Tris- $\mathrm{HCl}, \mathrm{pH} 7.5$ to an $\mathrm{OD}_{600}$ of 0.05 . Changes in fluorescence were continuously monitored using a RF-5300PC spectrofluorometer (Shimadzu, Kyoto, Japan) at an excitation wavelength of $622 \mathrm{~nm}$ and an emission wavelength of $670 \mathrm{~nm}$. The bacterial 


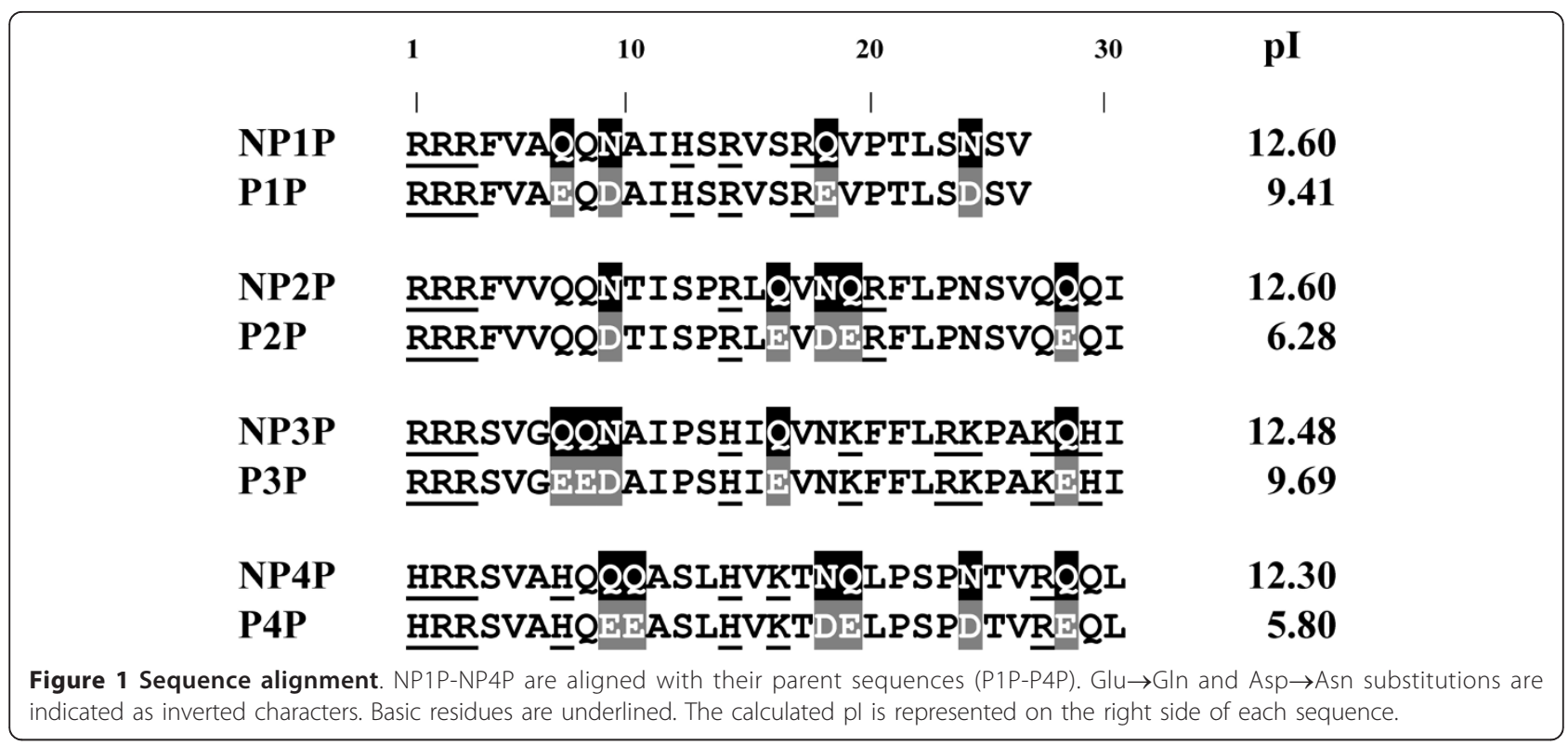

suspension was incubated with $400 \mathrm{nM}$ diS- $\mathrm{C}_{3}$-(5). Test peptides were added to the bacterial suspension after the dye uptake was maximal. The maximal increase in fluorescence due to disruption of the cytoplasmic membrane was recorded.

\section{Liposome disruption assay}

Membrane-disrupting activity was estimated by liposome disruption assay [19]. Bovine heart phosphatidylglycerol (PG), egg cardiolipin (CL), and egg phosphatidylcholine (PC) were purchased from Avanti Polar Lipids, Inc., Alabama, USA. A lipid film was prepared by rotary evaporation of lipid solution (1 $\mathrm{mg}$ lipid in $1 \mathrm{ml}$ chloroform). The lipid film was hydrated with $1 \mathrm{ml}$ of $10 \mathrm{mM}$ Tris$\mathrm{HCl}$ buffer (pH 7.5) containing $75 \mathrm{mM}$ calcein. Lipid dispersions were sonicated and subjected to five freeze-thaw cycles. Non-trapped calcein was removed by gel filtration on a Sephacryl S-300 spin column (GE Healthcare BioScience Corp., Piscataway, NJ, USA) equilibrated with $10 \mathrm{mM}$ Tris- $\mathrm{HCl}$ (pH 7.5) containing $175 \mathrm{mM} \mathrm{NaCl}$ and $1 \mathrm{mM}$ EDTA. These calcein-entrapped liposomes were diluted at a ratio of 1:1000 in $10 \mathrm{mM}$ Tris- $\mathrm{HCl}(\mathrm{pH} 7.5)$ containing $350 \mathrm{mM}$ sucrose. Calcein release after membrane disruption was evaluated by measuring fluorescence intensity at $515 \mathrm{~nm}$ with excitation at $492 \mathrm{~nm}$ on a RF-5300PC spectrofluorometer at room temperature.

\section{Circular dichroism (CD) spectroscopy}

CD spectra were recorded on a J-720 spectropolarimeter (JASCO, Tokyo, Japan) in the far-ultraviolet (UV) range from 190 to $260 \mathrm{~nm}$ using a $0.1 \mathrm{~cm}$ thermostatted cell at $25^{\circ} \mathrm{C}$. Peptides were dissolved in $10 \mathrm{mM}$ Tris- $\mathrm{HCl}$ (pH 7.5) containing tri-fluoroethanol (TFE) at $0-100 \%$.
For measurement under the presence of liposomes, peptides were dissolved at $100 \mu \mathrm{g} / \mathrm{ml}$ containing $500 \mu \mathrm{g} / \mathrm{ml}$ liposomes at $20^{\circ} \mathrm{C}$.

\section{Results and Discussion \\ Microbicidal activities}

The pro-region of cecropin P1-P4 (P1P-P4P) and the acid-amide-substituted mutants (acidic residues neutralized P1P-P4P: NP1P-NP4P) were chemically synthesized. The $\mathrm{C}$-terminal- $\mathrm{COOH}$ was not modified. The minimum bactericidal concentrations (MBCs) for these peptides were estimated (Table 1). Parent peptides (P1P-P4P) were not bactericidal at $\leq 300 \mu \mathrm{g} / \mathrm{ml}$ except for weak activities of P3P. These results were expected from the inhibitory effects of pro-regions to the activity of mature peptides [16]. NP1P-NP3P displayed bactericidal activity against all tested Gram-positive bacteria $(S$. aureus IFO12732, B. subtilis IFO3134, and M. luteus IFO12708), some Gram-negative bacteria ( $P$. aeruginosa IFO3899, S. typhimurium IFO13245, and E. coli JM109), and a yeast (S. cerevisiae MAFF113011). The Gramnegative bacterium, $S$. marcescens IFO3736, was not susceptible. NP3P was the most effective among these peptides (e.g., $\mathrm{MBC}=5 \mu \mathrm{g} / \mathrm{ml}$ against $S$. aureus IFO12732). The MBCs of NP1P-NP3P were comparable with those of mature nematode cecropins, which are well-recognized, potent, natural CAMPs [15]. These results suggest that the acid-amide substitution effectively confers bactericidal activities to some tested parent peptides. Only NP4P was not bactericidal at $\leq 300$ $\mu \mathrm{g} / \mathrm{ml}$ against all the tested microbes although enhancer activity for membrane-disruptive antimicrobial peptides was detected [19]. 
Table 1 Minimum bactericidal concentrations (MBCs) of NP1P-NP4P and their parent peptides

\begin{tabular}{lcccc}
\hline Microbes & \multicolumn{4}{c}{ MBC, $\mathbf{\mu g} / \mathbf{m l}$} \\
& $\begin{array}{c}\text { NP1P } \\
\text { (P1P) }\end{array}$ & $\begin{array}{c}\text { NP2P } \\
\text { (P2P) }\end{array}$ & $\begin{array}{c}\text { NP3P } \\
\text { (P3P) }\end{array}$ & NP4P \\
\hline Gram-positive bacteria & & & & \\
Staphylococcus aureus IFO12732 & 10 & 5 & 5 & $>300$ \\
& $(>300)$ & $(>300)$ & $(>300)$ & $(>300)$ \\
Bacillus subtilis IFO3134 & 30 & 70 & 20 & $>300$ \\
& $(>300)$ & $(>300)$ & $(>300)$ & $(>300)$ \\
Micrococcus luteus IFO12708 & 30 & 30 & 10 & $>300$ \\
& $(>300)$ & $(>300)$ & $(200)$ & $(>300)$ \\
Gram-negative bacteria & & & & \\
Pseudomonas aeruginosa & 20 & 70 & 20 & $>300$ \\
IFO3899 & $(>300)$ & $(>300)$ & $(70)$ & $(>300)$ \\
Salmonella typhimurium & 30 & 200 & 20 & $>300$ \\
IFO13245 & $(>300)$ & $(>300)$ & $(>300)$ & $(>300)$ \\
Serratia marcescens IFO3736 & $>300$ & $>300$ & $>300$ & $>300$ \\
& $(>300)$ & $(>300)$ & $(>300)$ & $(>300)$ \\
Escherichia coli JM109 & 10 & 30 & 7 & $>300$ \\
Yeasts & $(>300)$ & $(>300)$ & $(>300)$ & $(>300)$ \\
Sacchoromyces cerevisiae & & & & \\
MAFF113011 & 200 & 100 & 7 & $>300$ \\
& $(>300)$ & $(>300)$ & $(>300)$ & $(>300)$ \\
\hline & & & &
\end{tabular}

\section{Conformational analyses}

Next, we examined if the acid-amide substitution would cause conformational changes by using CD spectroscopy (Figure 2). Far-UV CD spectra of NP1P-NP3P were similar to those of their parent peptides P1P-P3P at various concentration of TFE. Interestingly, the profile of TFE-dependent change of $\mathrm{A}_{222} / \mathrm{A}_{208}$ displayed a characteristic meta-stable phase around 50\% TFE both for NP1P-NP3P and P1P-P3P series. These results suggest that NP1P-NP3P acquire microbicidal activity by acidamide substitution without remarkable conformational changes. Since the acid-amide substitution is expected to be "structurally conservative", our strategy could be applicable for design of novel CAMPs from natural nonantimicrobial sequences which contain structures distinct from known CAMPs.

\section{Mode of action}

To elucidate the mode of action against living microbial cells, the relationship between membrane-disruption and bacterial killing activities of NP1P-NP3P was assessed for Staphylococcus aureus IFO12732 (Figure 3). NP1P-NP3P destroyed S. aureus membrane at $<1 / 10$ concentration of MBC although P1P-P3P were neither membrane-disruptive nor bactericidal. Moreover, these peptides killed bacteria in almost parallel fashion with their membrane disruption activities. These results suggest that the bactericidal activities of all the NP1P-NP3P peptides against $S$. aureus are accomplished via membrane-disruption. In contrast, only slight haemolytic activities were detected for NP1P-NP3P, suggesting that the membrane disruptive activities were selective against microbial membranes (Table 2).

\section{Membrane-disruptive activities against acidic-liposomes}

Furthermore, membrane-disruptive activities against liposomes were also estimated. A liposome dye-leakage assay was used. P1P-P3P did not cause the dye-leakage at $\leq 300 \mu \mathrm{g} / \mathrm{ml}$ against the liposome membrane [molar ratio of phosphatidylglycerol (PG):cardiolipin (CL) was 3:1], which was negatively charged and mimicked the Grampositive cytoplasmic membrane, and the liposome membrane consisting of only phosphatidylcholine (PC), which was neutrally charged and mimicked eukaryotic membranes. Far-UV CD spectra of P3P were almost identical under the presence and absence of PG/CL liposomes, suggesting that those peptides were not inserted into hydrophobic regions of liposome membranes [20]. In contrast, NP2P and NP3P damaged the PG/CL liposome membrane at $\geq 0.3 \mu \mathrm{g} / \mathrm{ml}$ (Figure 4 ). The concentration was equal or lower than MBCs against Gram-positive bacteria, which were measured under identical ionic conditions. NP3P $(100 \mu \mathrm{g} / \mathrm{ml})$ was precipitated under the presence of higher concentration of PG/CL liposome $(500 \mu \mathrm{g} / \mathrm{ml})$ although P3P was not affected under the same condition, suggesting that NP3P acquired strong interaction with PG/CL membrane by acid-amide substitutions. Since CD spectra could not be measured, the conformation of NP3P in the presence of PG/CL membrane remains unclear. NP2P and NP3P did not affect $\mathrm{PC}$ liposome membrane (data not shown), suggesting that NP2P and NP3P selectively attack the negatively charged membrane as usually found in bacteria. This observation agreed with that those peptides did not destroy erythrocyte membranes. It is noteworthy that NP3P exhibited stronger bactericidal properties but weaker membrane disruptive activities against PG/CL membranes than those of NP2P, i.e., activities against PG/CL were not parallel to those against $S$. aureus membrane. In addition, NP1P did not exhibit membranedisruptive activity in PG/CL and PC membranes at $\leq 200 \mu \mathrm{g} / \mathrm{ml}$. These results suggest that membranedisruptive activities of NP1P-NP3P are highly diversified against PG/CL membranes although all of those peptides are strongly harmful against $S$. aureus membrane. The nematode cecropin pro-region is expected to be a unique and promising skeleton for novel synthetic CAMPs with diversified membrane-discriminative properties, i.e., CAMPs which exhibit distinct target-selectivity may be generated using this skeleton.

\section{Conclusions}

The acid-amide substitution successfully generated some novel CAMPs in our trial study. These novel CAMPs 

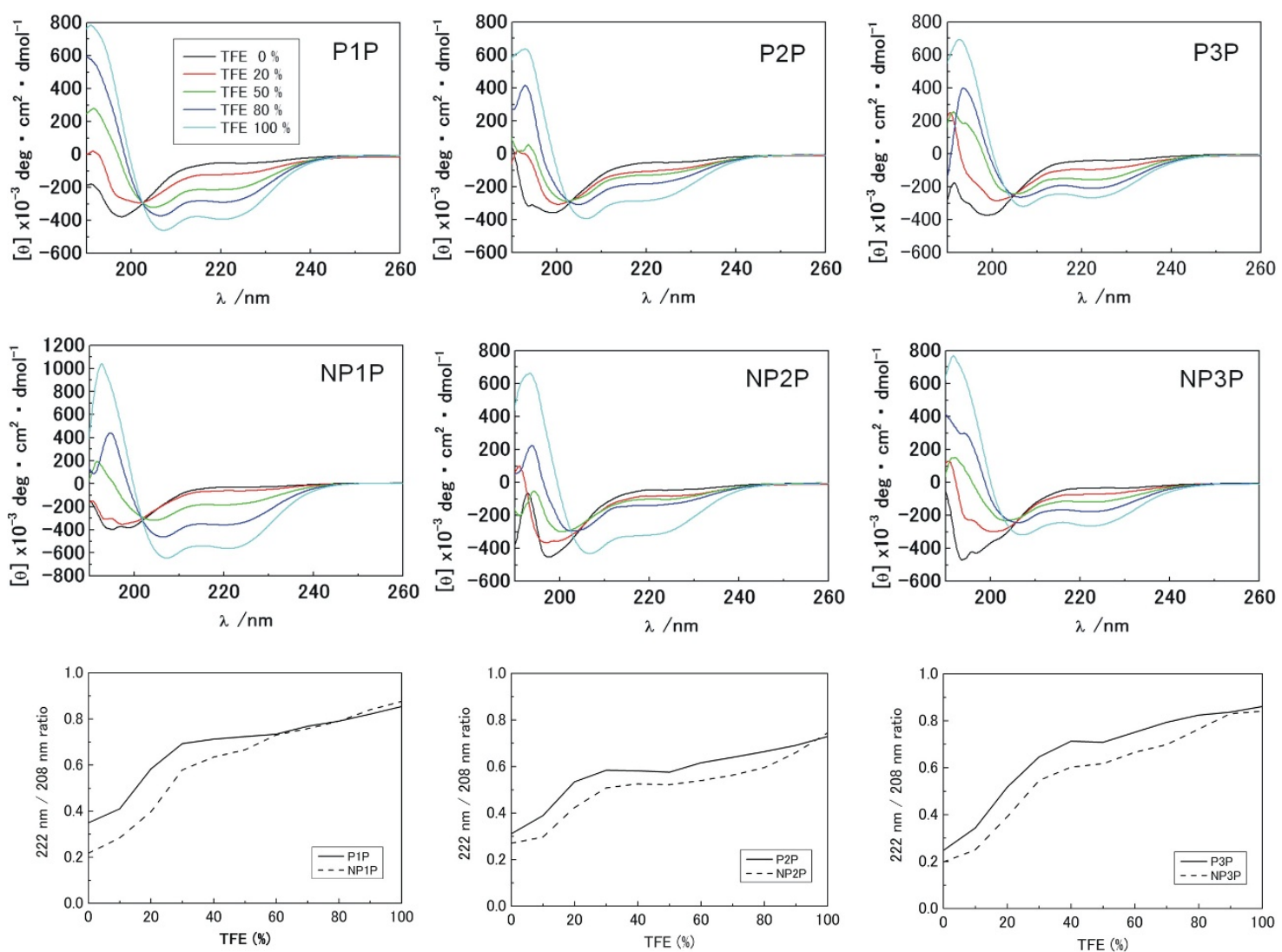

Figure 2 TFE-dependent change of far-UV CD spectra. NP1P-NP3P and P1P-P3P were examined. CD spectra in the presence of 0-100\% TFE. The profiles of TFE-dependent change of $A_{222} / A_{208}$ are also represented.
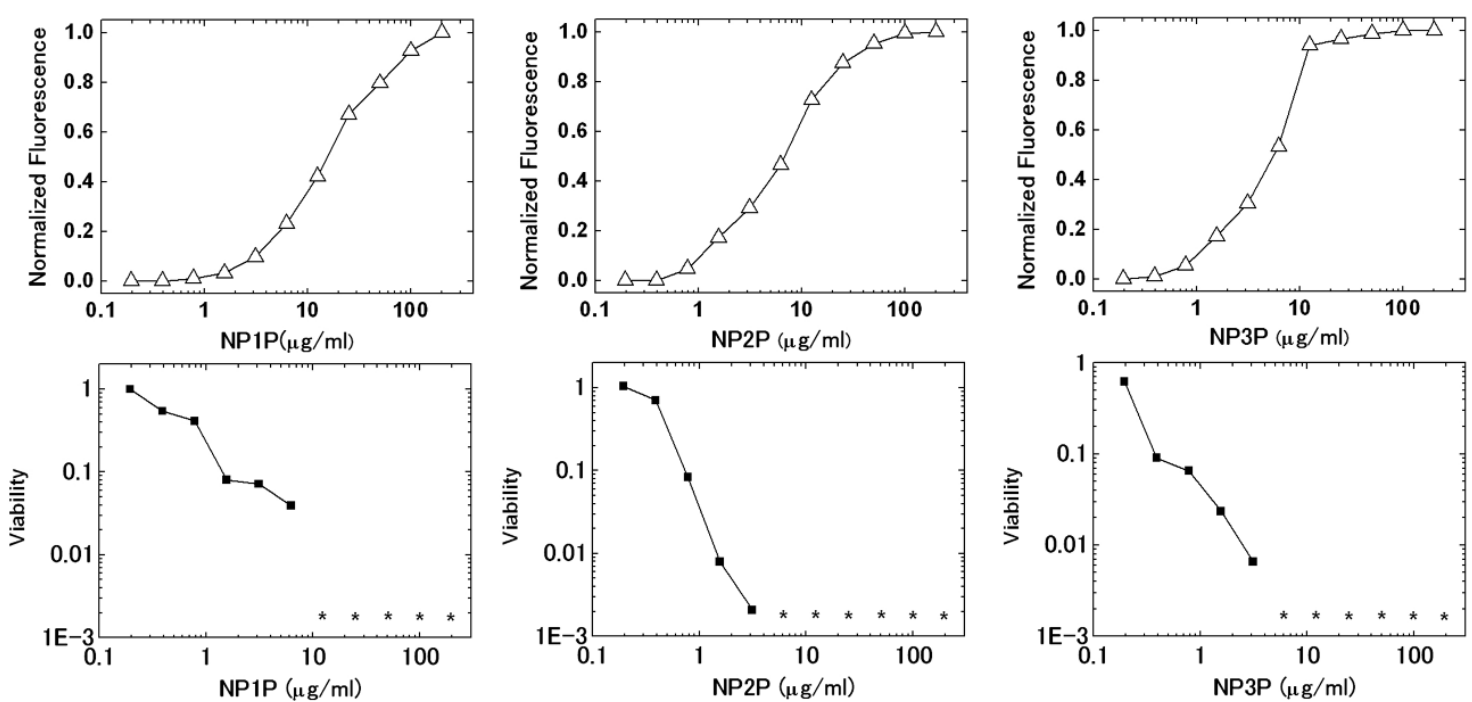

Figure 3 Dose-membrane disruption and -bactericidal effect curve of NP1P-NP3P against S. aureus IFO12732. These curves were simultaneously determined. The asterisks indicate that viable cells were not detected. Disruption of the cytoplasmic membrane was estimated by the increase in fluorescence intensity of $\mathrm{diS}_{-} \mathrm{C}_{\mathbf{3}}-(5)$. Changes in fluorescence were normalized by the value at the plateau of the doseresponse curves. 
Table 2 Hemolytic activity of NP1P-NP3P and their parent peptides

\begin{tabular}{lll}
\hline Agent & Concentration $(\mu \mathrm{g} / \mathrm{mL})$ & Hemolytic activity (\%) \\
\hline NP1P (P1P) & 300 & $1.32 \pm 0.02(0.00 \pm 0.00)$ \\
NP2P (P2P) & 300 & $3.48 \pm 0.01(0.00 \pm 0.01)$ \\
NP3P (P3P) & 300 & $2.61 \pm 0.02(1.69 \pm 0.05)$ \\
amphotericin B & 30 & $82.5 \pm 7.2$ \\
\hline
\end{tabular}

were derived from natural non-antimicrobial sequences, and their sequences were completely distinct from any categories of known CAMPs. In addition, remarkable conformational changes were not detected between parent and substituted peptides although further study was necessary to estimate the conformation in the presence of membranes. This observation suggested that acid-amide substitution was a promising method to generate novel skeletons of CAMPs from natural nonantimicrobial sequences that have structures distinct from known CAMPs. This platform should not be limited to acid-amide substitution or natural parent sequences. Combination with limited introduction of basic residues and/or use of chimera sequences with some natural sequences might expand the flexibility of this platform.

Acid-amide substitution occurs at a high frequency in the mutations of natural proteins [21]. Such substituted residues could be accommodated in the structure and function of the parent proteins. The accumulation of acid-amide substitutions and gain of net positive charge could occasionally confer antimicrobial activities. This is a presumable scenario for the birth of natural CAMPs.

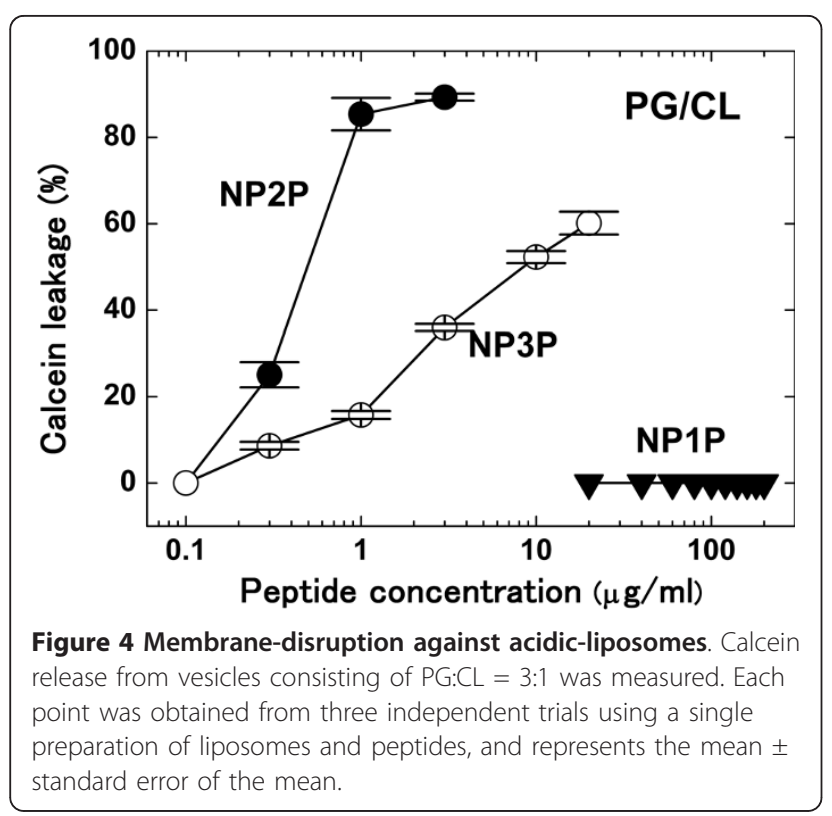

\section{Acknowledgements}

This work was partly funded by research fellowships of the Japan Society for the Promotion of Science for Young Scientists.

\section{Author details}

${ }^{1}$ National Institute of Agrobiological Sciences, Oowashi 1-2, Tsukuba, Ibaraki 305-8634, Japan. ²SAITO Research Center, Peptide Institute, Inc., Ibaraki,

Osaka 567-0085, Japan.

\section{Authors' contributions}

SU and MM carried out the microbicidal assays, hemolytic assays,

cytoplasmic membrane permeability assays, and liposome disruption assays. YT participated in the liposome disruption assays. TY, YN, and MT carried out the CD spectroscopy experiments. YK conceived of the study, participated in its design and coordination, and drafted the manuscript. All authors read and approved the final manuscript.

\section{Competing interests}

The authors declare that they have no competing interests.

Received: 7 September 2010 Accepted: 22 March 2011

Published: 22 March 2011

\section{References}

1. Brogden KA: Antimicrobial peptides: pore formers or metabolic inhibitors in bacteria? Nat Rev Microbiol 2005, 3:238-350.

2. Zelezetsky I, Tossi A: Alpha-helical antimicrobial peptides-Using a sequence template to guide structure-activity relationship studies. Biochim Biophys Acta 2006, 1758:1436-1449.

3. Blondelle SE, Takahashi E, Dinh KT, Houghten RA: The antimicrobial activity of hexapeptides derived from synthetic combinatorial libraries. J Appl Bacteriol 1995, 78:39-46.

4. Hilpert K, Volkmer-Engert R, Walter T, Hancock RE: High-throughput generation of small antibacterial peptides with improved activity. Nat Biotechnol 2005, 23:1008-1012.

5. Rausch JM, Marks JR, Rathinakumar R, Wimley WC: Rational combinatorial design of pore-forming beta-sheet peptides. Proc Natl Acad Sci USA 2005, 102:10511-10515.

6. Xie Q, Matsunaga S, Wen Z, Kumano M, Sakakibara Y, Machida S: In vitro system for high-throughput screening of random peptide libraries for antimicrobial peptides that recognize bacterial membranes. J Pept Sci 2006, 12:643-652.

7. Loit $E$, Wu K, Cheng $X$, Hincke MT, Altosaar I: Functional whole-colony screening method to identify antimicrobial peptides. J Microbial Methods 2008, 75:425-431.

8. Fjell CD, Jenssen $H$, Hilpert $K$, Cheung WA, Panté N, Hancock RE, Cherkasov A: Identification of novel antibacterial peptides by chemoinformatics and machine learning. J Med Chem 2009, 52:2006-2015.

9. Jian H, Yarbrough DK, Kreth J, Anderson MH, Shi W, Eckert R: Systematic approach to optimizing specificifically targeted antimicrobial peptides against Streptococcus mutans. Antimicrob Agents Chemother 2010, 54:2143-2151.

10. Blondelle SE, Takahashi E, Weber PA, Houghten RA: Identification of antimicrobial peptides by using combinatorial libraries made up of unnatural amino acids. Antimicrob Agents Chemother 1994, 38:2280-2286.

11. Radzishevsky I, Krugliak M, Ginsburg H, Mor A: Antiplasmodial activity of lauryl-lysine oligomers. Antimicrob Agents Chemother 2007, 51:1753-1759.

12. Chongsiriwatana NP, Patch JA, Czyzewski AM, Dohm MT, Ivankin A, Gidalevitz D, Zuckermann RN, Barron AE: Peptoids that mimic the structure, function, and mechanism of helical antimicrobial peptides. Proc Natl Acad Sci USA 2008, 105:2794-2799.

13. Lee JY, Boman A, Sun CX, Andersson M, Jornvall H, Mutt V, Boman HG: Antibacterial peptides from pig intestine: isolation of a mammalian cecropin. Proc Natl Acad Sci USA 1989, 86:9159-9162.

14. Andersson MA, Boman A, Boman HG: Ascaris nematodes from pig and human make three antibacterial peptides: isolation of cecropin P1 and two ASABF peptides. Cell Mol Life Sci 2003, 60:599-606.

15. Pillai A, Ueno S, Zhang H, Lee JM, Kato Y: Cecropin P1 and novel nematode cecropins: a bacteria-inducible antimicrobial peptide family in the nematode Ascaris suum. Biochem J 2005, 390:207-214. 
16. Ueno S, Kusaka K, Tamada Y, Minaba M, Zhang H, Wang PC, Kato Y: Anionic C-terminal proregion of nematode antimicrobial peptide cecropin P4 precursor inhibits antimicrobial activity of the mature peptide. Biosci Biotechnol Biochem 2008, 72:3281-3284.

17. Zhang $\mathrm{H}$, Morikawa $\mathrm{K}$, Ohta $\mathrm{T}$, Kato $\mathrm{Y}$ : In vitro resistance to the CSaß-type antimicrobial peptide ASABF- $a$ is conferred by overexpression of sigma factor sigB in Staphylococcus aureus. J Antimicrob Chemother 2005, 55:686-691.

18. Zhang H, Yoshida S, Aizawa T, Murakami R, Suzuki M, Koganezawa N, Matsuura A, Miyazawa M, Kawano K, Nitta K, Kato Y: In vitro antimicrobial properties of recombinant ASABF, an antimicrobial peptide isolated from the nematode Ascaris suum. Antimicrob Agents Chemother 2000, 44:2701-2705.

19. Ueno S, Kusaka K, Tamada Y, Zhang H, Minaba M, Kato Y: An enhancer peptide for membrane-disrupting antimicrobial peptides. BMC Microbiol 2010, 10:46.

20. Chou HT, Wen HW, Kuo TY, Lin CC, Chen WJ: Interaction of cationic antimicrobial peptides with phospholipid vesicles and their antibacterial activity. Peptides 2010, 31:1811-1820.

21. Jones DT, Taylor WR, Thornton JM: The rapid generation of mutation data matrices from protein sequences. Comput Appl Biosci 1992, 8:275-282.

doi:10.1186/1476-0711-10-11

Cite this article as: Ueno et al: Generation of novel cationic antimicrobial peptides from natural non-antimicrobial sequences by acid-amide substitution. Annals of Clinical Microbiology and Antimicrobials 2011 10:11

\section{Submit your next manuscript to BioMed Central} and take full advantage of:

- Convenient online submission

- Thorough peer review

- No space constraints or color figure charges

- Immediate publication on acceptance

- Inclusion in PubMed, CAS, Scopus and Google Scholar

- Research which is freely available for redistribution

Submit your manuscript at www.biomedcentral.com/submit 